\title{
Management preferences and attitudes regarding environmental impacts from seawater desalination: Insights from a small coastal community
}

\author{
Nadine Heck ${ }^{a, *}$, Adina Paytan ${ }^{a, b}$, Donald C. Potts ${ }^{c}$, Brent Haddad ${ }^{d}$, Karen Lykkebo \\ Petersen $^{b}$ \\ a Institute of Marine Sciences, University of California, Santa Cruz, 1156 High Street, \\ Santa Cruz, CA, 95064, USA \\ b Department of Earth and Planetary Sciences, University of California, Santa Cruz, 1156 \\ High Street, Santa Cruz, CA, 95064, USA \\ c Department of Ecology and Evolutionary Biology, University of California, Santa Cruz, \\ 1156 High St., Santa Cruz, CA, 95064, USA \\ d Environmental Studies, University of California, Santa Cruz, 1156 High St., Santa Cruz, \\ CA, 95064, USA
}

\section{Abstract}

The use of seawater desalination as a water supply option is increasing worldwide. Compared to other marine sectors, studies on marine users' perceptions and attitudes towards this new sector and its impacts on marine ecosystems are very limited. This study assessed differences in coastal stakeholder groups' preferences for managing marine impacts of a seawater desalination plant in a small coastal community. The majority of respondents placed high importance on the marine ecosystem, including ecosystem features that are less visible and charismatic, and were highly concerned about potential impacts on marine ecosystems and marine activities from the new desalination facility. Coastal residents further rated multiple management measures to reduce and off-set marine impacts as highly important, but indicated a lack of trust in institutions involved in regulating and managing environmental impacts. Logistic regression revealed that lack of institutional trust and concerns about marine impacts were significant predictors of opposition to the desalination facility and appeared to play a critical role in shaping local attitudes towards desalination. Findings further revealed that local opinions were primarily shaped by how respondents used the nearby marine system, and by gender. Age, education, and race did not seem to shape local opinions. At the same time, there were differences between consumptive and nonconsumptive marine user groups' opinions indicating the potential for conflict regarding the most important management strategies.

This is the accepted manuscript of a paper published in Ocean and Coastal Management. The final version may be accessed at https://doi.org/10.1016/j.ocecoaman.2018.05.024. 


\section{Introduction}

As water demand in many regions worldwide has surpassed availability of potable freshwater, seawater desalination is increasingly being integrated into freshwater supply (Dolnicar and Schäfer, 2009). According to the International Desalination Association (IDA), more than 18,000 seawater desalination plants were in operation in 2015, with a global capacity of more than 86 million cubic meters per day (International Desalination Association, 2015).

In the US, seawater desalination is an emerging ocean resource sector that is likely to grow in the future. Water supply from surface and groundwater sources has become increasingly unreliable in many coastal areas due to increased demand, saltwater intrusion into aquifers, and changing weather patterns (Bourne, 2008; Mirchi et al., 2013; Sellers, 2008; Heberger et al., 2009). California, with about nine proposed seawater desalination projects, is currently the state with the highest number of proposed seawater desalination plants in the US (State Water Resources Control Board, 2014; Pacific Institute, 2012). Seawater desalination is particularly valued for its ability to provide a reliable source of water even during extended drought conditions (Gibson et al., 2015; Morgan, 2017). At the same time, seawater desalination remains controversial due to high economic costs and environmental impacts related to seawater intake and brine discharge (Liu et al., 2013, Cooley et al., 2013, Fuentes-Bargues, 2014, Haddad, 2013).

Indirect environmental impacts on marine ecosystems, such as ocean acidification and sea-level rise, may occur due to the high energy consumption of desalination plants and subsequent increase in greenhouse gas emissions (Cooley and Heberger, 2013; Miller et al., 2015). Seawater intake and brine discharge from desalination plants add stresses to marine environments that may already be affected by a variety of anthropogenic activities (Halpern et al., 2008; Lattemann and Höpner, 2008). Examples of direct environmental impacts include degradation of marine habitats (e.g., loss of sea grass beds) mortality of bottom-dwelling organisms, coastal eutrophication, changes in seawater quality due to brine discharge, changes in microbial communities and microbial productivity when exposed to brine discharge, and mortality of larvae and other organisms due to impingement and entrainment during seawater intake (DelPilar-Ruso et al., 2008; de-laOssa-Carretero et al., 2016; Belkin et al., 2015; Lattemann and Höpner, 2008).

Another consideration for seawater desalination plants are potential effects on marine protected areas that are increasingly being established around the world. One example in the US is the Marine Protected Area (MPA) network along the coast of California. This network is the first of its kind in the US and consists of 124 individual MPAs intended to safeguard the productivity and diversity of marine life and habitats for current and future generations (Natural Resources Defense Council, 2014). Seawater intake and brine discharge from desalination plants close to MPAs could have impacts on protected ecosystems within individual MPA sites and compromise the effectiveness of the broader MPA network (Natural Resources Defense Council, 2014). Furthermore, the technology could lead to impacts on recreational and commercial activities, but these impacts have not been systematically studied 
to date (Monterey Bay National Marine Sanctuary and National Marine Fisheries Service, 2010; Liu et al., 2013).

Measures that can reduce impacts from brine discharge include development and enforcement of national pollution standards specific to contaminants found in desalination brine (including salinity thresholds) and multi-port diffusers to promote mixing at the point of discharge. Another option is the dilution of brine with effluent from a wastewater treatment plant or cooling water from a power plant (State Water Resources Control Board, 2014), which could become a less vital option in California due to an increasing interest in wastewater recycling. Mitigation measures that can help offset environmental impacts can be either in-kind or out-ofkind measures. In-kind-mitigation replaces the same types of ecosystem features that were lost (e.g., by creating new estuarine habitats if estuarine species are killed during water intake) (Ambrose, 1994; State Water Resources Control Board, 2014). Out-of-kind mitigation replaces lost features with dissimilar ones, for example not replacing all species impacted by entrainment (Ambrose, 1994; Stratus Consulting, 2004; State Water Resources Control Board, 2014). Examples include restoring up-stream habitats, adding to existing marine protected areas, or paying mitigation fees to programs that enhance viability and sustainability of marine life (Foster et al., 2012; State Water Resources Control Board, 2014).

Understanding local opinions on this technology and its impacts is important in order to account for local preferences in the development of these plants. It further offers insights into social acceptability and support (Innes and Booher, 2004; Intergovernmental Panel on Climate Change, 2001; Gopnik et al., 2012; Thomassin et al., 2010). Scientific understanding of societal values and attitudes towards marine ecosystems and the use of marine resources is, however, still in its infancy, especially with regard to citizens who are not part of organized stakeholder groups, even though the public can have substantial influences on coastal development and management decisions (Potts et al., 2016; Marre et al., 2016).

Literature on attitudes towards seawater desalination is still limited. Previous studies explored mostly the acceptance to use of desalinated water (e.g., Dolnicar et al., 2011; Dolnicar et al., 2010; Dolnicar and Schäfer, 2009; Theodori et al., 2009). These studies have been informed by theoretical approaches in social psychology and psychological risk perception literature (e.g., Ajzen and Fishbein, 1988; Pidgeon and Beattie, 1998) and found that perceived environmental impacts, costs, quality of desalinated water and associated health concerns are the main concerns with the use of desalinated water, in addition to socioeconomic variables (Dolnicar and Schäfer, 2009; Dolnicar et al., 2011).

Studies on attitudes towards desalination plants detected wide concerns about environmental issues from desalination (Domènech et al., 2013) and assessed the influence of attitudinal and socio-demographic factors on public voting behavior for or against additional desalination plants in Perth in 2007 and 2012 (Gibson et al., 2015). More detailed analysis of perceptions of specific environmental impacts and how these perceptions influence attitudes towards desalination have not been carried out. In addition, an understanding of how differences 
in perceptions and management priorities of marine users are connected to specific marine impacts of desalination plants is lacking.

This study addresses this gap by investigating coastal residents' perceptions and preferences for managing marine impacts of a seawater desalination facility in a small coastal community in Southern California. In particular, the study investigates the importance of the local marine ecosystem to coastal residents, identifies concerns about impacts from the desalination facility, and assesses preferred management options to reduce these impacts. In addition, the study explores how far these variables shape attitudes towards the local plant. Perceptions of threats to water supply and health in the context of using desalinated water have been found to influence attitudes towards the technology (Dolnicar et al., 2011; Mankad and Tapsuwan, 2011) and hence are not addressed here. Our study explores if perceived threats to the local marine environment and marine activities influenced the degree of support for the desalination facility. The study also identifies the influence of socio economic variables and marine user patterns on perceptions and attitudes and investigates if there are any differences in perceptions and attitudes among consumptive and non-consumptive marine user groups.

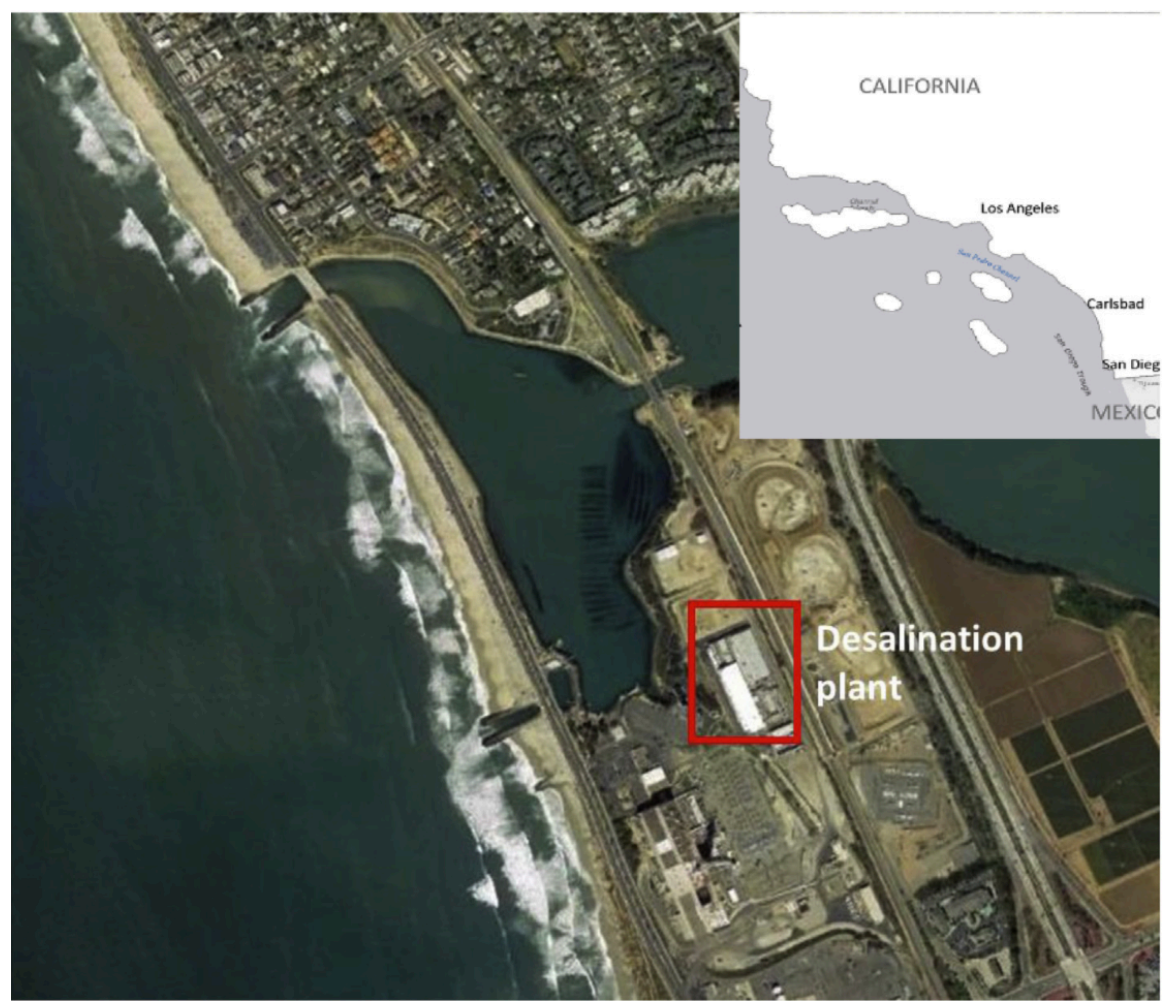

Fig. 1. Location of the desalination plant in Carlsbad, California (small map indicates location of Carlsbad in Southern California).

\section{Methods}

\subsection{Case study location}

Carlsbad, a seaside community with 112,299 residents (2016) in Southern California (Fig. 1), receives fresh water from the San Diego County Water Authority (SDCWA), which receives 
approximately $64 \%$ of its drinking water from the Colorado River, $20 \%$ from the State Water Project in northern California, and only 16\% from local sources (Anderson, 2015). To diversify its water portfolio, SDCWA entered into a 30-year water purchase agreement with a private investor, Poseidon Resources, starting in December 2015 (San Diego County Water Authority, 2014).

The newly constructed desalination plant is located in an industrial area along the coast on the southern end of a 162 ha man-made, shallow coastal lagoon, the Agua Hedionda Lagoon, part of which is used for mussel and oyster aquaculture. The lagoon contains four main habitat types - marshlands, upland plant communities, intertidal mudflats, and subtidal habitats and supports a rich and diverse ecosystem. Both the lagoon and offshore areas are popular for fishing, paddle boarding, kayaking, beach walking, wildlife viewing (including nearby whale watching), recreational boating, and surfing. The offshore marine area adjacent to the plant site is part of the geographic zone known as the Southern California Bight (SCB), which encompasses about $56,979 \mathrm{~km}^{2}$ from Point Conception in the north to Cabo Colnett in Baja California in the south. The coast adjacent to the plant consists of 50-70 $\mathrm{m}$ wide beaches backed in places by marine terrace bluffs. Important habitats in the area include intertidal sand habitats, subtidal soft bottom habitats, and subtidal hard bottom habitats. Abundant organisms in these habitats include clams, snails, polychaeta worms, arthropods (crabs and shrimp), fish and plankton and kelp beds are abundant offshore.

At full capacity, the seawater desalination plant pumps about 300 million gallons per day (mgd) of seawater indirectly via an open ocean intake technology (Poseidon Water, 2008; California Water Boards, 2014). The intake and outfall facilities are shared with the adjacent Encina power plant, while the power plant is still in operation. Specifically, water for the desalination plant is taken from the return flow of the powerplant cooling water, meaning no new intake was required for the new desalination facility. The desalination process uses $100 \mathrm{mgd}$ of seawater to produce $50 \mathrm{mgd}$ of high quality drinking water via seawater reverse osmosis, and $50 \mathrm{mgd}$ of salty brine with a concentration of about 67,000 ppm (about twice the concentration of incoming seawater). This brine is combined with the rest of the powerplant thermal effluent ( $\sim 200 \mathrm{mgd}$ ) for dilution prior to discharge into the coastal ocean through a discharge pond with an open channel. Chemicals used in cleaning processes are discharged to the sanitary sewer system for treatment and disposal, and not directly into the ocean (Poseidon Water, 2008).

Since seawater desalination is a relatively new sector in California, regulations for reducing impacts on marine areas are still in the early stages of development. One step in this direction was the amendment of the California Ocean Plan to establish guidelines for regulating intake and discharge from desalination plants, which was enacted in 2015 (SRWCB, 2014). Mitigation measures to offset impacts are typically reviewed and approved by an interagency team on a case-by-case basis (State Water Resources Control Board, 2015). In this case, the plant operator had to develop a marine life mitigation plan to address entrainment impacts caused by water intake. The plan includes restoration of about 15-22 ha of estuarine wetlands in the Southern California Bight (Poseidon Water, 2008) to fulfill the conditions of the permits issued by the California Coastal Commission and the Regional Water Quality Control Board. 


\subsection{Questionnaire-based survey}

Data were collected using a questionnaire-based survey between March and May 2015 to identify factors that shape coastal residents' attitudes towards the seawater desalination plant. At the time of the study, the desalination plant had finished construction but had not started operation.

Questionnaires were administered by mail to a sample of 1500 residents in Carlsbad, California. The sample was randomly selected from postal records. Questionnaires were distributed using three mailings following Dillman et al. (2014). The first and third mailings consisted of a cover letter, a booklet style questionnaire, and a prepaid return envelope. The second mailing consisted of a postcard reminder to residents who had not responded to the first mailing. The third mailing was sent only to addresses that had either not responded to the survey or were returned as undeliverable in the first or second mailings (Vaske, 2008). The total sample size was 331 with a response rate of $25 \%$ after accounting for undeliverable mail $(n=159)$. This response rate is consistent with similar mail surveys asking the public about natural resource issues (Perry et al., 2014; Connelly et al., 2003; Vaske, 2008).

The questionnaire included closed questions about the importance of the marine ecosystem, concerns about impacts of the plant on marine areas in California and in Carlsbad, the importance of mitigation measures to reduce impacts on marine areas, and trust in organizations to implement mitigation measures (Table 1). In addition, we assessed frequency of engagement in marine activities and socio-demographic information (Table 2).

Table 1. Description of variables and coding.

\begin{tabular}{|l|l|}
\hline Variable & Description and coding \\
\hline Importance of marine ecosystem & $\begin{array}{l}\text { 5-point scale from not at all important (1) } \\
\text { to extremely important (5) }\end{array}$ \\
\hline $\begin{array}{l}\text { Concerns about desalination impact on local } \\
\text { marine ecosystem and activities }\end{array}$ & $\begin{array}{l}5 \text { point scale from not concerned at all (1) } \\
\text { to extremely concerned (3) }\end{array}$ \\
\hline Perception of management measures & $\begin{array}{l}5 \text { point scale from not at all important (1) } \\
\text { to extremely important (5) }\end{array}$ \\
\hline Trust in organizations to manage impacts & $\begin{array}{l}5 \text { point scale from do not trust (1) to } \\
\text { extremely trust (5) }\end{array}$ \\
\hline
\end{tabular}

\section{Results}

\subsection{Importance of marine ecosystem features and concerns about marine} impacts

Coastal residents rated local marine ecosystem features as being important including features that are less visible such as benthic flora and fauna and small marine organisms such as algae and fish larvae (Fig. 2). 
Table 2. Socio-demographic profile and frequency of ocean use $(\mathrm{N}=331)$.

\begin{tabular}{|l|l|l|l|}
\hline Variable & Coding & \% respondents & Mean value \\
\hline Gender & Male (1) & $55.5 \%$ & \\
\hline Age & Female (0) & $44.5 \%$ & \\
\hline & Continuous & & 56.9 \\
\hline & $18-34$ & $9.7 \%$ & \\
\hline & $35-60$ & $44.8 \%$ & \\
\hline Education & $>61$ & $45.5 \%$ & \\
\hline & University degree (1) & $72.9 \%$ & \\
\hline Member NGO & Otherwise (0) & $27.3 \%$ & \\
\hline & Yes (1) & $12.7 \%$ & \\
\hline Ethnicity & No (0) & $87.3 \%$ & \\
\hline & White (1) & \\
\hline Frequency of ocean use & Other (0) & $87.2 \%$ & \\
\hline$-\quad$ Fishing & Ordinal & \\
\hline$-\quad$ Surfing/swimming & & & 2.44 \\
\hline$-\quad$ Boating & & & 1.73 \\
\hline$-\quad$ Wildlife viewing & & & 2.83 \\
\hline$-\quad$ Beach walks & & & 1.91 \\
\hline- Shellfish harvesting & & & 3.18 \\
\hline
\end{tabular}

a Measured on a 5-point scale 1= Never to 5 = Almost every day.

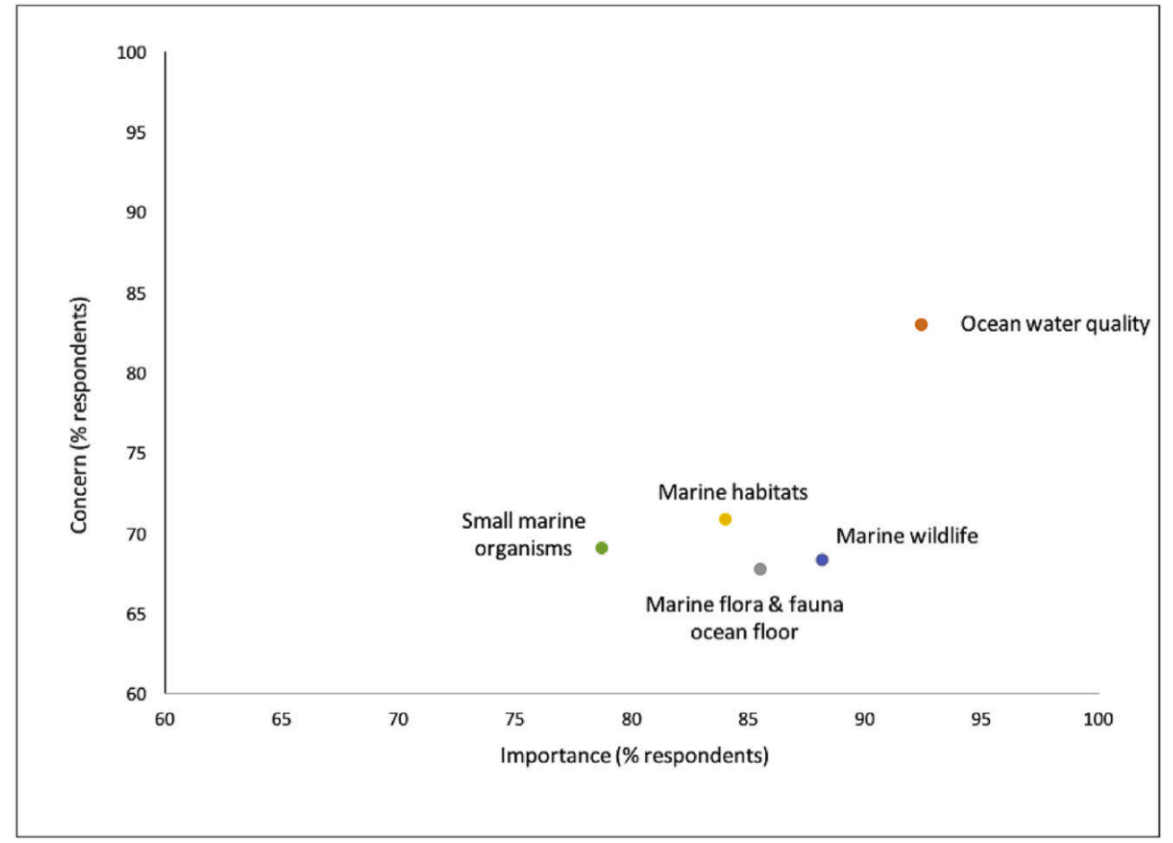

Note: \% respondents indicating moderate to high importance and being somewhat to extremely concerned.

Fig 2. Perceived importance of and concern about impacts on local marine ecosystem (\% respondents). 


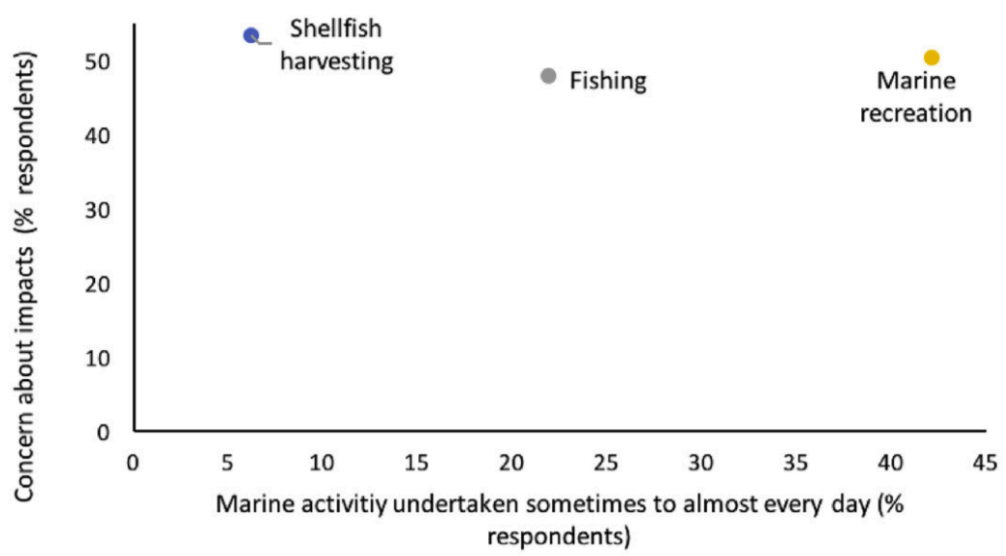

Note: \% of respondents somewhat to extremely concerned, \% of respondents engaging in marine activity sometimes to almost every day.

Fig. 3. Concerns about the impacts on marine activities (\% respondents).

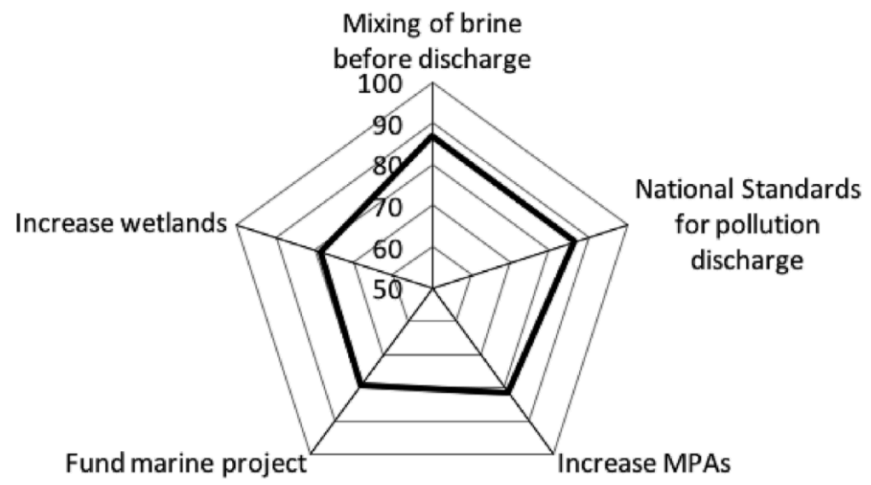

Fig 4. Importance of management measures for reducing impacts of brine discharge on marine ecosystem (\% of respondents who consider the measure to be somewhat to extremely important).

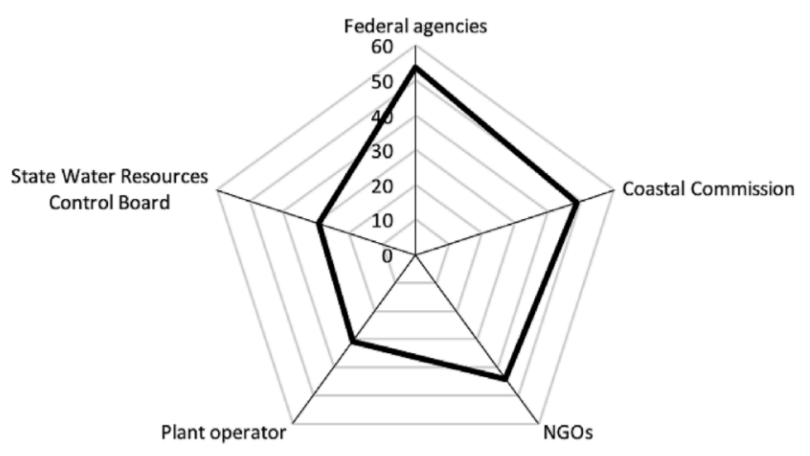

$\%$ respondents for somewhat trust to extremely trust

Fig. 5. Trust in organizations to implement management measures ( $\%$ of respondents). 
Correlation analysis indicated that coastal residents were most concerned about impacts on marine ecosystem features that they valued most highly (Spearman's rho $=0.531, p<0.001$ ). The greatest concern was about potential impacts on ocean water quality followed by concern about impacts on biological features (e.g., loss of small marine organisms that are captured during water intake, fish species abundance, marine wildlife).

More than half of all residents were concerned about impacts on local marine activities that depend on the local marine environment such as shellfish harvesting in aquaculture operations in the lagoon adjacent to the plant, fishing, and recreation (Fig. 3).

\subsection{Management of impacts and institutional trust}

Coastal residents rated all measures to reduce impacts of brine discharge as important, with an emphasis on measures that reduce rather than offset impacts (Fig. 4).

When asked about trust in agencies to manage potential impacts, about $50 \%$ of respondents reported that they trust federal agencies including the US Environmental Protection Agency (EPA) and National Oceanic and Atmospheric Administration (NOAA) to manage impacts. Only about $30 \%$ of respondents trusted the plant operator and the State Water Resources Control Board to do so (Fig. 5).

\subsection{The influence of marine user patterns and socio-demographic variables on local perceptions}

Linear regression analysis revealed that ocean use was a significant predictor for placing high importance on marine features and for high concerns about impacts to the marine environment and marine activities (Table 3).

Education and race did not regress significantly with any variable, but gender and age had some influence on marine values and concerns about potential impacts. Female respondents were more concerned and placed higher values on the marine ecosystem than men. Age as a separate variable regressed significantly with the importance of the marine ecosystems, with younger respondents expressing a higher importance.

Ocean use was a significant predictor for assigning importance to implementation of management measures to reduce marine impacts from the plant. Gender was the only sociodemographic variable that regressed significantly with management preferences and institutional trust. Female respondents expressed higher importance for mitigation measures and higher levels of trust (Table 4).

\subsection{Predictors of support for desalination plant}

Logistic regression analysis revealed that institutional trust and concerns about impacts on the marine ecosystem were negatively correlated with support for the desalination plant (Table 5). Concerns about impacts on human activities and environmental management preferences had no effect on attitudes towards the new plant. 
Table 3. Linear regression coefficients for importance of the local marine ecosystem and concerns about marine impacts.

\begin{tabular}{|c|c|c|c|c|c|c|c|c|c|}
\hline & \multicolumn{3}{|c|}{ Importance marine features ${ }^{a}$} & \multicolumn{3}{|c|}{ Concern marine impacts ${ }^{b}$} & \multicolumn{3}{|c|}{$\begin{array}{l}\text { Concern impacts \& marine } \\
\text { activities }^{c}\end{array}$} \\
\hline & $\mathrm{B}$ & Beta & $p$ & $\mathrm{~B}$ & Beta & $p$ & $\mathrm{~B}$ & Beta & $p$ \\
\hline (Constant) & 4.370 & & .000 & 2.730 & & .000 & 1.316 & & .029 \\
\hline Race & -.031 & -.014 & .811 & .221 & .050 & .405 & .089 & .021 & .735 \\
\hline Ocean use & .227 & .202 & $.001 *$ & .433 & .195 & .002 & .600 & .277 & $.000 * *$ \\
\hline Age & -.007 & -.145 & $.019 *$ & -.002 & -.019 & .764 & .003 & .029 & .651 \\
\hline Gender & -.206 & -.138 & $.019 *$ & -.587 & -.199 & .001 & -.279 & -.097 & .110 \\
\hline Education & -.073 & -.044 & .454 & -.140 & -.042 & .476 & -.101 & -.031 & .605 \\
\hline
\end{tabular}

$* \mathrm{p}<0.05 ; * * \mathrm{p}<0.001$.

a $R=0.312, R 2=0.098 ;$ adjusted $R=0.081 ; F=5.838 ; p<0.001$.

${ }^{b} R=0.289, R 2=0.084 ;$ adjusted $R=0.066 ; F=4.799 ; p<0.001$.

c $R=0.287, R 2=0.082 ;$ adjusted $R=0.065 ; F=54.630 ; p<0.001$.

Table 4. Linear regression coefficients for importance of mitigation measures and trust.

\begin{tabular}{|l|l|l|l|l|l|l|}
\hline & \multicolumn{2}{|l|}{ Mitigation measures $^{\mathrm{a}}$} & \multicolumn{2}{l|}{ Trust $^{\mathrm{b}}$} \\
\cline { 2 - 7 } & $\mathrm{B}$ & Beta & $\mathrm{p}$ & $\mathrm{B}$ & Beta & $\mathrm{p}$ \\
\hline (Constant) & 3.508 & & 0.000 & 3.754 & & 0.000 \\
\hline Race & -0.015 & -0.004 & 0.945 & -0.186 & -0.071 & 0.250 \\
\hline Ocean use & 0.244 & 0.141 & $0.033^{*}$ & -0.127 & -0.094 & 0.142 \\
\hline Age & 0.001 & 0.008 & 0.898 & 0.000 & -0.006 & 0.925 \\
\hline Gender & -0.558 & -0.243 & $0.000^{* *}$ & -0.322 & -0.180 & $0.004^{*}$ \\
\hline Education & -0.023 & -0.009 & 0.884 & 0.124 & 0.063 & 0.306 \\
\hline
\end{tabular}

${ }^{*} \mathrm{p}<0.05 ; * * \mathrm{p}<0.001$.

a $R=0.270, R 2=0.073 ;$ adjusted $R=0.054 ; F=3.876 ; p<0.0$.

b $R=0.226, R 2=0.051 ;$ adjusted $R=0.033 ; F=2 . ; p 772 ;<0.05$.

Table 5. Logistic regression coefficients for desalination support ${ }^{\mathrm{a}}(\mathrm{N}=273)$.

\begin{tabular}{|l|l|l|l|l|}
\hline & B & S.E. & \multicolumn{1}{|c|}{$\operatorname{Exp(B)}$} & $p$ \\
\hline Marine ecosystem importance & -0.522 & 0.303 & 0.593 & 0.085 \\
\hline Concern marine ecosystem impacts & -0.800 & 0.224 & 0.450 & $0.000^{* *}$ \\
\hline Concern marine activity impacts & 0.116 & 0.152 & 1.123 & 0.444 \\
\hline Importance management measures & -0.060 & 0.243 & 0.942 & 0.804 \\
\hline Institutional trust & 0.408 & 0.176 & 1.503 & $0.020^{*}$ \\
\hline Constant & 4.876 & 1.357 & 131.06 & 0.000 \\
\hline
\end{tabular}

-2 Log likelihood = 266.814; Cox and Snell $R^{2}=0.227$; Negelkerke $R^{2}=0.320$.

${ }^{*} \mathrm{p}<0.05 ;{ }^{* *} \mathrm{p}<0.001$.

${ }^{\text {a }}$ Dummy coded 1 = support/strongly support, $0=$ otherwise. 
Table 6. Spearman's rho correlation coefficients perceptions of marine user groups.

\begin{tabular}{|l|l|l|}
\hline & Fishing & Marine recreation \\
\hline Marine ecosystem importance & 0.055 & $0.310^{* *}$ \\
\hline Concerns marine ecosystem impacts & 0.014 & $0.249^{* *}$ \\
\hline Concerns marine use impacts & & \\
\hline $\begin{array}{l}\text { Regulatory measures to reduce impacts (pollution and salinity discharge } \\
\text { standards) }\end{array}$ & -0.043 & $0.136^{*}$ \\
\hline $\begin{array}{l}\text { Mitigation measures to off-set impacts (creation of wetlands, MPAs, } \\
\text { mitigation banks) }\end{array}$ & -0.065 & $0.201^{* *}$ \\
\hline Trust $\quad$ Plant operator & & \\
\hline$-\quad$ State organizations & -0.052 & $-0.189^{* *}$ \\
\hline$-\quad$ Federal agencies & $-0.145^{*}$ & $-0.126^{*}$ \\
\hline$-\quad$ NGOs & $0.189^{* *}$ & $-0.173^{* *}$ \\
\hline Support desalination pant & $-0.116^{*}$ & 0.029 \\
\hline & $-0.112^{*}$ & $-0.168^{* *}$ \\
\hline
\end{tabular}

${ }^{*} p<0.05 ; * *<0.001$.

\subsection{Differences in marine user group perceptions and attitudes}

Additional analysis revealed differences in perceptions among nonconsumptive and nonsumptive marine users (Table 6). Nonconsumptive use was significantly and positively correlated with a high importance of the local marine ecosystem and impacts on this system and on dependent marine activities. Fishing was only correlated with high concerns about impacts on marine activities and particularly fishing. Distinct marine user patterns also correlated significantly with management preferences and institutional trust. Non-consumptive use was correlated with putting high importance to the implementation of management measures to reduce impacts from the plant and low trust in the private sector plant operators. Fishing in contrast was negatively correlated with institutional trust in federal and state governmental agencies.

The influence of institutional trust and environmental concerns on attitudes may explain underlying reasons for opposition among marine user groups (Table 6). Fishermen may not support the plant due to a lack of trust in organizations to manage impacts whereas recreational users are more likely to oppose the plant due to concerns about impacts on the marine ecosystems coupled with a lack of institutional trust.

\section{Discussion}

Coastal management typically requires accounting for multiple perspectives and preferences, including those of the public both broadly and located near proposed new facilities. In the case of seawater desalination, public acceptance and priorities are playing an important role in the development of this new sector. Our study yields multiple insights into local opinions on seawater desalination and its impacts on marine ecosystems and marine-based activities.

Coastal residents rate local marine ecosystem features as very important, including features that are less visible and less charismatic. This finding is consistent with results in previous 
studies that found that members of the public place importance on many species, not just charismatic flagship species such as marine mammals (Jefferson et al., 2014; Montgomery, 2002). In our study, coastal residents valued not only marine species but also environmental features, such as ocean water quality and habitats, and were more concerned about desalination impacts on these features than on marine activities that could reduce enjoyment of local marine areas. These findings suggest that the public in coastal areas values the ocean beyond visible and charismatic species and that people are concerned about new and complex impacts on marine ecosystems, even if these impacts have no immediate implications for people themselves.

Environmental concerns and organizational trust are critical factors in the development of coastal resource sectors, such as desalination, as concerns about environmental impacts and lack of trust in regulatory bodies reduced support for the technology in this study. Concerns about environmental impacts of desalination have also been reported in previous studies on public perceptions of seawater desalination in Australia and the US (King et al., 2012; Heck et al. 2016, 2017) and seem to be an important factor shaping public attitudes towards this sector. Previous studies also reported low levels of public trust in agencies to manage marine areas (e.g., Hynes et al., 2014; Potts et al., 2011; Gelcich et al., 2014). Whereas these studies did not explore the influence of institutional trust on attitudes towards specific ocean sectors, our study finds that institutional trust is shaping public attitudes towards seawater desalination and could be critical to gain public support for this new technology. A potential explanation for the low level of trust in institutions could be a lack of community engagement that allows for twoway communication (Innes and Booher, 2004; Gray et al., 2012). In the case of seawater desalination, more direct engagement with the public and marine stakeholders that allows for interactive discussions could increase trust in institutions and ultimately support for seawater desalination.

In addition, the study finds that marine user patterns rather than socio-demographic variables shape local opinions. Coastal communities with an avid marine user community thus may have different opinions on desalination compared to communities where people don't engage frequently in marine activities. At the same time, the type of marine use seems to play a role as we detected multiple differences in opinions of consumptive and non-consumptive marine users. Engagement strategies meant to increase trust among existing marine user groups thus need to be tailored to specific groups. Fishermen, for example, may distrust multiple organizations due to previous negative experience on other marine issues (e.g. over fishing regulations and restrictions) since a history of adverse relationships has been found to reduce trust in agencies (Innes and Booher, 2004; Gray et al., 2012). Measures to increase trust by the fishing community in agencies that manage marine impacts thus may have to consider the wider context in which fisheries operate.

The study also finds that both consumptive and non-consumptive ocean use are linked to reduced support for seawater desalination but the underlying reasons may be different. As institutional trust was a significant predictor for support for the desalination facility, fishermen 
may oppose desalination due to their low institutional trust. Recreational users on the other hand may oppose the plant due to high concerns about impacts on the local marine ecosystem, which was also a significant predictor for opposition of the new facility. Eliciting not only whether different groups support or oppose the plant but why they do so is important to a better understanding of marine user groups' perceptions and attitudes towards new ocean sectors such as seawater desalination and for developing communication materials that are targeted to the needs of each audience.

\section{Conclusions}

Water districts in coastal regions are investigating and proposing seawater desalination to increase the availability and reliability of freshwater supplies. Our study suggests that more efforts are needed to understand and account for local views on seawater desalination since coastal residents' views may not be in line with efforts to reduce the impacts of a local desalination plant. We detected distinct opinions among different marine users on seawater desalination, which suggests that coastal managers need to elicit distinct marine users' opinions. Further, management agencies need to make greater efforts to engage more with coastal residents, and particularly the fishing community, to address the low level of trust in government organizations and NGOs to manage impacts on marine ecosystems and marine uses. And finally, long-term environmental and socio-economic effects of desalination plants and their mitigation measures on nearby residents and users of marine resources are also not well understood. One potential line of research would be to look at the magnitude and spatial impacts of these issues to inform long-term management strategies and to provide information to coastal residents and marine user groups about impacts of desalination on marine ecosystems, including the effectiveness of mitigation measures to reduce or offset these impacts.

\section{Acknowledgements}

The study was funded by the National Science Foundation Coastal SEES program, award 1325649 to A.P, D.P., and B.H.

\section{Appendix A. Supplementary data}

Supplementary data related to this article can be found at http://dx.doi.org/10.1016/j.ocecoaman.2018.05.024.

\section{References}

Ajzen, I., Fishbein, M., 1988. Theory of Reasoned Action-Theory of Planned Behavior. University of South Florida.

Ambrose, R.F., 1994. Mitigating the effects of a coastal power plant on a kelp forest community: rationale and requirements for an artificial reef. Bull. Mar. Sci. 55 (2-3), 694-708.

Anderson, E., 2015. Drinking water starts flowing from Carlsbad desalination plant. KPBS 
12/14/15. http://www.kpbs.org/news/2015/dec/14/what-you-need-to-knowabout-carlsbaddesalination/, Accessed date: 17 December 2015.

Belkin, N., Rahav, E., Elifantz, H., Kress, N., Berman-Frank, I., 2015. Enhanced salinities, as a proxy of seawater desalination discharges, impact coastal microbial communities of the eastern Mediterranean Sea. Environ. Microbiol. 17 (10), 4105-4120. http://dx.doi.org/10.1111/1462-2920.12979.

Bourne, G., 2008. California Desalination Planning Handbook. California State University Sacramento: Sacramento: Center for Collaborative Policy.

California Water Boards, 2014. Desalination Facility Intakes, Brine Discharges, and the Incorporation of Other Nonsubstantive Changes Sacramento. State of California, Environmental Protection Agency.

Connelly, N.A., Brown, T.L., Decker, D.J., 2003. Factors affecting response rates to natural resource-focused mail surveys: empirical evidence of declining rates over time. Soc. Nat. Resour. 16 (6), 541-549.

Cooley, H., Ajam, N., Heberger, M., 2013. Key Issues in Seawater Desalination in California: Marine Impacts. Pacific Institute, Oakland, CA.

Cooley, H., Heberger, M., 2013. Key Issues in Seawater Desalination in California: Energy and Greenhouse Gas Emission. Pacific Institute, Oakland, CA.

de-la-Ossa-Carretero, J.A., Del-Pilar-Ruso, Y., Loya-Fernández, A., Ferrero-Vicente, L.M., Marco-Méndez, C., Martinez-Garcia, E., Sánchez-Lizaso, J.L., 2016. Response of amphipod assemblages to desalination brine discharge: impact and recovery. Estuar. Coast Shelf Sci. 172, 13-23.

Del-Pilar-Ruso, Y., De-la-Ossa-Carretero, J.A., Giménez-Casalduero, F., Sánchez-Lizaso, J.L., 2008. Effects of a brine discharge over soft bottom Polychaeta assemblage.

Environ. Pollut. 156 (2), 240-250.

Dillman, D.A., Smyth, J.D., Christian, L.M., 2014. Internet, Phone, Mail, and Mixed-mode Surveys: the Tailored Design Method. John Wiley \& Sons.

Dolnicar, S., Hurlimann, A., Grün, B., 2011. What affects public acceptance of recycled and desalinated water? Water Res. 45 (2), 933-943.

https://doi.org/10.1016/i.watres.2010.09.030.

Dolnicar, S., Hurlimann, A., Nghiem, L.D., 2010. The effect of information on public acceptance - the case of water from alternative sources. J. Environ. Manag. 91 (6), 1288-1293. https://doi.org/10.1016/i.jenvman.2010.02.003. 
Dolnicar, S., Schäfer, A.I., 2009. Desalinated versus recycled water: public perceptions and profiles of the accepters. J. Environ. Manag. 90 (2), 888-900.

https://doi.org/10.1016/j.jenvman.2008.02.003.

Domènech, L., March, H., Saurí, D., 2013. Degrowth initiatives in the urban water sector? A social multi-criteria evaluation of non-conventional water alternatives in Metropolitan Barcelona. J. Clean. Prod. 38, 44-55. https://doi.org/10.1016/j.jclepro.2011.09.020.

Foster, M., Cailliet, G., Callaway, J., Raimondi, P., Stienbeck, J., 2012. Mitigation and Fees for the Intake of Seawater by Desalination and Power Plants. State Water Resources Control Board, Sacramento, CA.

Fuentes-Bargues, J.L., 2014. Analysis of the process of environmental impact assessment for seawater desalination plants in Spain. Desalination 347, 166-174.

https://doi.org/10.1016/j.desal.2014.05.032.

Gelcich, S., Buckley, P., Pinnegar, J., Chilvers, J., Lorenzoni, I., Terry, G., Guerrero, M., Castilla, J., Valdebenito, A., Duarte, C., 2014. Public awareness, concerns, and priorities about anthropogenic impacts on marine environments. Proc. Natl. Acad. Sci. Unit. States Am. 111 (42), 15042-15047.

Gibson, F.L., Tapsuwan, S., Walker, I., Randrema, E., 2015. Drivers of an urban community's acceptance of a large desalination scheme for drinking water. J. Hydrol.

528, 38-44.

Gopnik, M., Fieseler, C., Cantral, L., McClellan, K., Pendleton, L., Crowder, L., 2012. Coming to the table: early stakeholder engagement in marine spatial planning. Mar. Pol. 36 (5), 1139-1149. https://doi.org/10.1016/j.marpol.2012.02.012.

Gray, S., Shwom, R., Jordan, R., 2012. Understanding factors that influence stakeholder trust of natural resource science and institutions. Environ. Manag. 49 (3), 663-674. http://dx.doi.org/10.1007/s00267-011-9800-7.

Haddad, B.M., 2013. A case for an ecological-economic research program for desalination. Desalination 324, 72-78.

Halpern, B.S., Walbridge, S., Selkoe, K.A., Kappel, C.V., Micheli, F., D'Agrosa, C., Bruno, J.F., Casey, K.S., Ebert, C., Fox, H.E., 2008. A global map of human impact on marine ecosystems. Science 319, 948-952. 